\title{
Pengelolaan Pemasaran Online UMKM Menghadapi Tatanan Kehidupan Baru Desa Banjarsari Kecamatan Manyar Kabupaten Gresik
}

\author{
Nashrudin Latif ${ }^{1}$, Edy Sulistiyawan ${ }^{2}$, R. Bambang Dwi Waryanto ${ }^{3,}$ Sugijanto $^{4}$, Siti \\ Istikhoroh $^{5}$
}

1,2* Program Studi Manajamen, Fakultas Ekonomi, Universitas PGRI Adi Buana Surabaya

3,4,5* Program Studi Akuntansi, Fakultas Ekonomi, Universitas PGRI Adi Buana Surabaya

Email : nashrudin@unipasby.ac.id

\begin{abstract}
ABSTRAK
Posisi strategis Usaha Mikro, Kecil, Menengah (UMKM) patut diapresiasi dalam menciptakan pertumbuhan ekonomi pedesaan khususnya Desa Banjarsari. Peran vital UMKM sangat dibutuhkan untuk menunjang rencana strategis pemerintahan desa membangun konsep Desa Wisata. Keterkaitan UMKM dengan konsep Desa Wisata memerlukan upaya bersama dalam mengembangkan produk lokal, salahsatunya melalui pemasaran online. Pemasaran online menjadi basis utama mensinergikan pengetahuan produk dan jasa kepada calon pengunjung Desa Wisata, sehingga dibutuhkan pengetahuan dan ketrampilan terkait penggunaan ragam media online sebagai sarana promosi produk dan jasa wisata bagi penduduk Desa Banjarsari. Kapasitas dan kemampuan warga desa Banjarsari dalam menjalankan aktivitas pemasaran online sangat beragam dari sisi demografi baik usia maupun pendidikan. Kesenjangan yang terjadi membutuhkan standar wawasan. Wawasan kebaruan dalam menghadapi tata kehidupan baru di masa pandemi menciptakan peluang munculnya kreasi Desa Wisata. Akselerasi kebutuhan pengetahuan dan ketrampilan standar pemasaran online tersebut diupayakan melalui program pengabdian kepada masyarakat, dengan memberikan penyuluhan dan pelatihan penggunaan media promosi secara online atas sumberdaya yang dimiliki oleh masyarakat Desa Banjarsari baik produk UMKM atau Desa Wisata yang ingin dikembangkan.
\end{abstract}

Kata kunci : Pemasaran Online, Media Promosi, Desa Wisata

\begin{abstract}
The strategic position of Micro, Small, Medium Enterprises (UMKM) should be appreciated in creating rural economic growth, especially in Banjarsari Village. The vital role of MSMEs is very much needed to support the strategic plan of village government to build the concept of a Tourism Village. The linkage of MSMEs with the concept of Tourism Village requires joint efforts in developing local products, one of which is through online marketing. Online marketing is the main basis for synergizing product and service knowledge to prospective visitors to the Tourism Village, so it requires knowledge and skills related to the use of various online media as a means of promoting tourism products and services for residents of Banjarsari Village. The capacities and abilities of Banjarsari villagers in carrying out online marketing activities vary widely in terms of demographics, both age and education. The gap that occurs requires a standard of insight. Newness insights in dealing with new life orders during a pandemic create opportunities for the creation of a Tourism Village. Acceleration of the need for standard online marketing knowledge and skills is pursued through community service programs, by providing counseling and training on the use of online promotional media for the resources owned by the people of Banjarsari Village, whether it is the UMKM or Tourism Village products that they want to develop.
\end{abstract}

Keywords: Online Marketing, Media Promotion, Tourism Village 


\section{PENDAHULUAN}

Potensi Desa Banjarsari sebagai bagian wilayah Kecamatan Manyar sangat menjanjikan untuk dikembangkan. Pengembangan potensi desa dapat berdampak pada kenaikan perekonomian masyarakat Desa (Susyanti, 2013). Aktivitas perekonomian desa setempat didominasi oleh budidaya perikanan tambak sebagai mata pencaharian utama masyarakat desa. Potensi besar tambak di Kabupaten Gresik, khususnya di kecamatan Manyar seluas 5.833,11 Ha sebagai sumberdaya yang melimpah. Salahsatu alasan utama Kabupaten Gresik pada tahun 2012 dijadikan kawasan percontohan pengembangan minapolitan budidaya perikanan di Jawa Timur. Salahsatu potensi desa yang memenuhi aspek penting khususnya bidang ekonomi melalui produk ikan bandeng dan udang.

Sektor UMKM Desa Banjarsari melalui produk ikan bandeng dan udang yang telah berkembang sebelumnya sebagai pintu masuk perkembangan tata kelola desa. Keberadaan UMKM diharapkan menopang rencana strategis Desa Banjarsari ke depan. Harapan baru di masa pandemi menumbuhkan ide pengembangan sektor lain melalui konsep desa wisata. Sinergi pertumbuhan UMKM dan konsep baru tersebut diharapkan mampu meningkatkan kesejahteraan masyarakat desa lebih luas jangkauan dan dampak sosial, budaya maupun ekonomi. Keterlibatan sektor UMKM mengisi potensi desa wisata dibutuhkan untuk lebih mengenalkan produk lokal pada sektor pariwisata.

Pengembangan ke depan kedua sektor yang saling mendukung terkendala aspek sumber daya manusia. Sumber daya manusia yang menggerakkan aktivitas perekonomian di masa pandemi dihadapkan pada masalah pemberlakuan protokol kesehatan yang memungkinkan minimnya transaksi bisnis secara langsung. Masalah tersebut didukung dengan belum adanya kemampuan dan kapasitas yang cukup untuk mengaitkan sektor UMKM yang sudah stabil dengan rencana strategis desa. Kesenjangan tata kelola pemasaran produk UMKM dan hubungannya dengan konsep desa wisata dapat diantisipasi dengan pemasaran secara online.

Media online merupakan basis peluang pengembangan produk-produk UMKM dan desa wisata. Pengguna media online mampu melahirkan social influencer produk pada generasi muda (Haniwati et.all, 2019). Potensi demografi desa Banjarsari yang layak diperhitungkan dan dikembangkan sebagai cara mewakili generasi tua andil dalam pemberdayaan masyarakat desa sekaligus mengurangi ketimpangan atas pengetahuan tentang teknologi berbasis internet. Peluang baru yang dapat menciptakan strategi agresif pelaku wisata melalui cara kerja e-marketing (Bambang, 2019). Pelaku wisata sebagai penggerak desanya membutuhkan solusi tata kelola yang baik dalam perencanaannya (Harjito, \& Nensi, 2018). Kesenjangan yang terjadi adalah minimnya kemampuan mengembangkan konsep desa wisata, promosi dan tata kelola kelembagaan sehingga optimalisasi potensi desa dapat terganggu.

Promosi sebagai bagian dari pemasaran, membutuhkan strategi pengembangan secara online sebagai solusi atas diberlakukannya peraturan Pemerintah tentang Pembatasan Sosial Berskala Besar (PSBB). Solusi yang ditawarkan memudahkan pemasaran produk UMKM tetap berjalan sekaligus memasarkan potensi desa wisata. Komunikasi pemasaran digital sebagai rancangan strategis mampu menggerakkan roda perekonomian desa wisata secara efektif (Kurnianti, 2018). Media internet sebagai promosi online dibuat melalui pengaktifan web e-commerce produk UMKM dan penunjang desa wisata (Lesmana, dkk, 2018). Sarana pemasaran online melalui media sosial seperti Facebook siginifikan mampu mendatangkan pengunjung ke desa wisata (Hasan, \& Setiyaningtiyas, 2015). Jejaring media sosial Facebook dan Instagram terbukti 
Jurnal Pengabdian Masyarakat

mampu menaikkan traffic kunjungan page penjualan online (Irfanudin, dkk, 2020). Peluang pemasaran online dengan potensi besar media online membutuhkan tindak lanjut melalui pemberian materi dan praktek dalam kegiatan mengabdi pada masyarakat (Edy,dkk, 2019).

\section{METODE PELAKSANAAN}

Kegiatan mengabdi masyarakat dilaksanakan dengan pendekatan deskriptif melalui eksplorasi bidang kajian yang ingin dikembangkan pada Desa Banjarsari. Kegiatan diskusi dan ceramah dalam penyuluhan dan pendampingan ditekankan untuk menemukan sumber masalah, menganalisis dan memberikan solusi alternatif secara bersama-sama antara Dosen dengan mitra Desa terkait. Upaya bersama diupayakan agar pemberdayaan masyarakat dapat ditumbuhkan melalui kesadaran kolektif, andil bagian dalam pembangunan desa setempat. Pola yang dilakukan yaitu (1) melakukan survey lokasi Desa Banjarsari, Kecamatan Manyar, Kabupaten Gresik, dilakukan untuk mengidentifikasi sumber masalah, menggali potensi desa dan upaya menjalin komunikasi; (2) melakukan sosialisasi materi dan diskusi, diharapkan untuk memberikan pengetahuan tentang pemasaran online serta dampak penggunaannya untuk peningkatan perekonomian sektor UMKM dan rencana strategis desa wisata; (3) melakukan penyuluhan dan pelatihan tentang penggunaan media online berbasis internet seperti pembuatan Website, Facebook dan Instagram serta media lainnya untuk menunjang efektifitas dan efesiensi program pemasaran online yang dijalankan; dan (4) melakukan feedback sebagai evaluasi dan monitoring secara berkala atas rangkaian kegiatan yang dilakukan.

\section{HASIL DAN PEMBAHASAN}

Keterkaitan pengembangan potensi UMKM desa Banjarsari dengan rencana strategis konsep desa wisata pada new normal di masa pandemi adalah peluang sinergis. Kolaborasi kedua sektor diharapkan mampu menunjang program desa dalam meningkatkan pertumbuhan ekonomi masyarakat desa. Kebutuhan tata kelola pemasaran produk lokal sebagai penguat rencana desa wisata dikembangkan melalui optimalisasi penggunaan media online sebagai sarana menawarkan produk dan sekaligus ajang mempromosikan desa wisata. Media promosi online dipaparkan kepada mitra masyarakat desa melalui pengenalan dan praktek penggunannya secara bertahap. Tahapan pertama yang dijalani peserta pelatihan dalam kegiatan pengabdian ini adalah media komunikasi untuk merumuskan agenda bersama (gambar 1). 
Jurnal Pengabdian Masyarakat

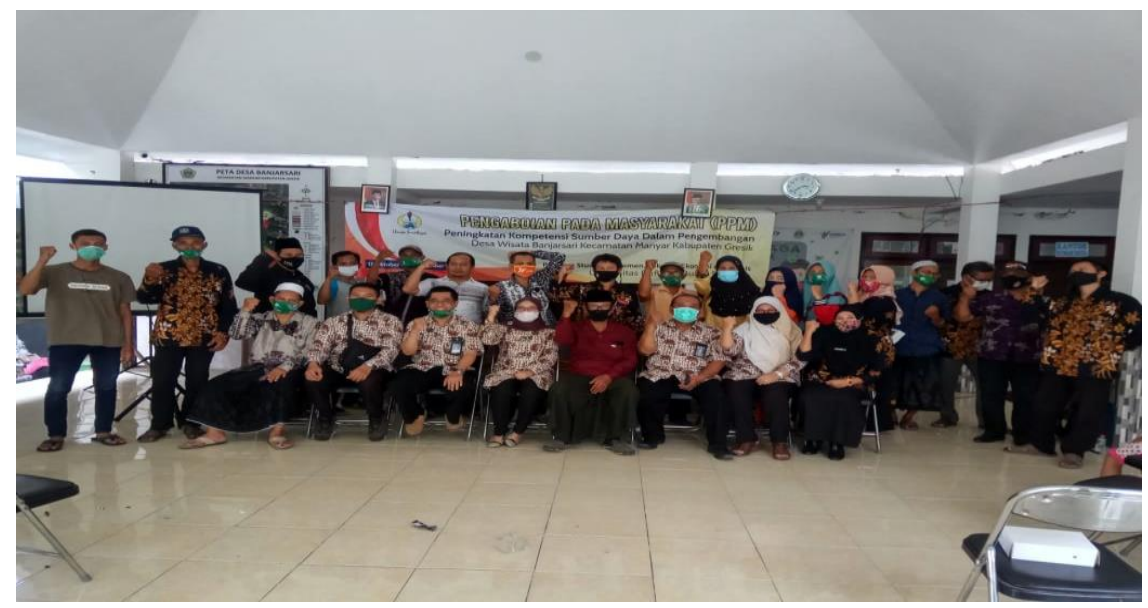

Gambar 1. Konsolidasi

Langkah kedua melalui konsolidasi diperlukan untuk menumbuhkan kebersamaan dalam memecahkan masalah. Masalah bersama yang dihadapi masyarakat desa adalah minimnya kemampuan menggunakan media pemasaran online secara optimal. Optimalisasi media online dijembatani dengan pemberian pengetahuan penting tentang beberapa pilihan dalam memasarkan produk secara online sekaligus media promosi desa wisata (Gambar 2). Program ini menjadi penting sebagai pondasi awal manfaat diberikannya materi dasar pemasaran online dan peluang yang didapat dalam penggunaannya. Kemampuan eksponensial media online mampu memberi dampak cakupan wilayah yang luas, peningkatan volume penjualan dan memudahkan akses informasi desa.

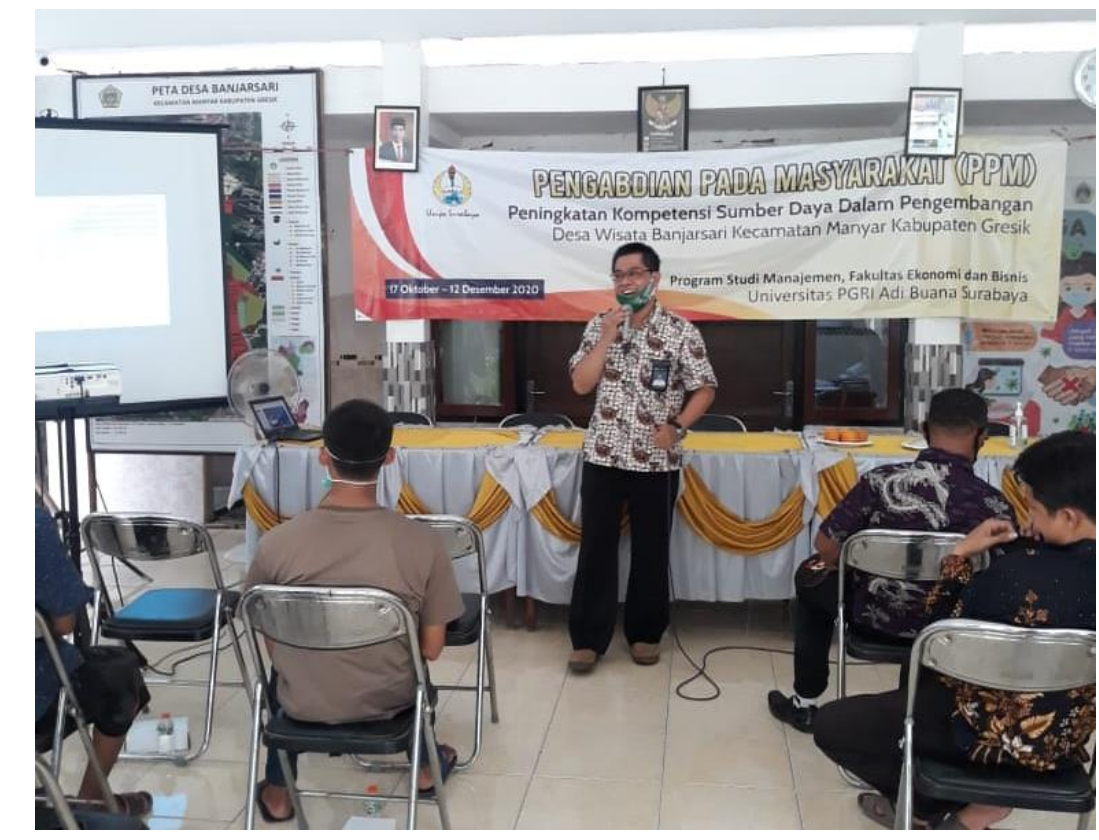

Gambar 2. Paparan Materi

Pengetahuan website sebagai media promosi produk UMKM diharapkan memberi pengaruh besar bagi perkembangan potensi desa Banjarsari sebagai langkah ketiga. Potensi UMKM dan desa wisata sebagai berkah baru di masa pandemi disinergikan 
Jurnal Pengabdian Masyarakat

dengan $e$-marketing dengan merancang website desa wisata sebagai stimulus atau desa percontohan (Gambar 3). Rancangan tersebut mendeskripsikan potensi yang dimiliki desa Banjarsari termasuk sosial, budaya, ekonomi dan pariwisata serta produk UMKM yang telah dikembangkan dengan baik sebelumnya. Mutualisme simbiosis antara keberadaan website dengan potensi lokal desa Banjarsari diharapkan memicu gairah investor datang untuk andil mengembangkan. Rancangan konten website memberikan deskripsi singkat potensi desa melalui beberapa menu penting yaitu beranda, event yang dijalankan atau direncanakan, destinasi spot-spot menarik yang dapat dikunjungi, kuliner untuk mendapatkan akses produk-produk olahan UMKM, akomodasi yang memuat informasi penginapan dan peta wisata sebagai alur proses penawaran produk atau jasa dalam konsep desa wisata. Informasi di website juga memberikan akses media sosial lain melalui Facebook, Instagram, Youtube dan media lain yang relevan untuk meningkatkan aksesbilitas users atau calon konsumen maupun investor untuk melakukan kunjungan di website.

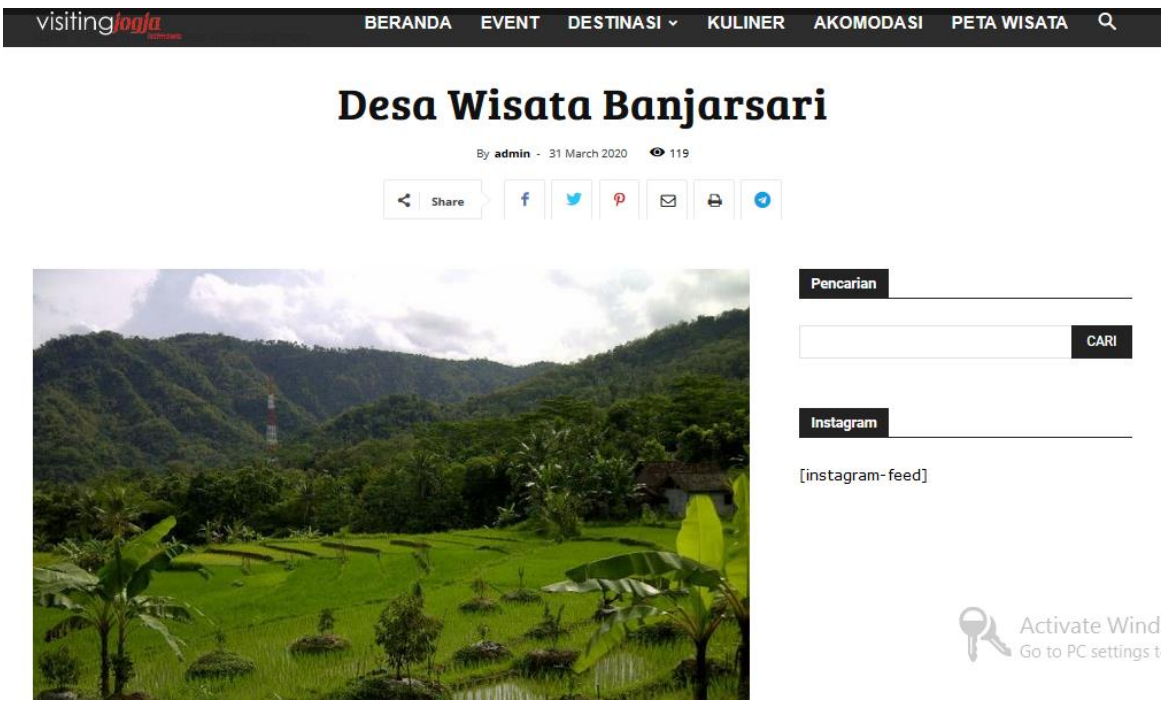

Gambar 3. Rancangan Website

Langkah keempat dalam optimalisasi peran pemasaran online melalui pengelolaan media sosial seperti Facebook dan Instagram. Potensi bonus demografi Desa Banjarsari memiliki jumlah generasi usia muda yang menguasai teknologi informasi melalui gadget. Kemampuan menggunakan sarana komunikasi berbasis internet menjadi peluang yang layak dikembangkan melalui ilustrasi percontohan desa wisata yang telah berkembang dengan baik (Gambar 4 dan 5). Aplikasi yang memudahkan penggunanya untuk melakukan searching produk untuk mendapatkan informasi apapun dan media mempromosikan produk atau jasa yang ditawarkan. Transaksi penjualan dengan media sosial sangat berpengaruh siginifikan baik dalam peningkatan pengunjung, kemudahan pemasaran dan penerimaan pendapatan. Pembelajaran membuat konten menarik lebih ditekankan secara bijak untuk menciptakan komunikasi yang berdampak positif dan informatif bagi netizen. 
Jurnal Pengabdian Masyarakat

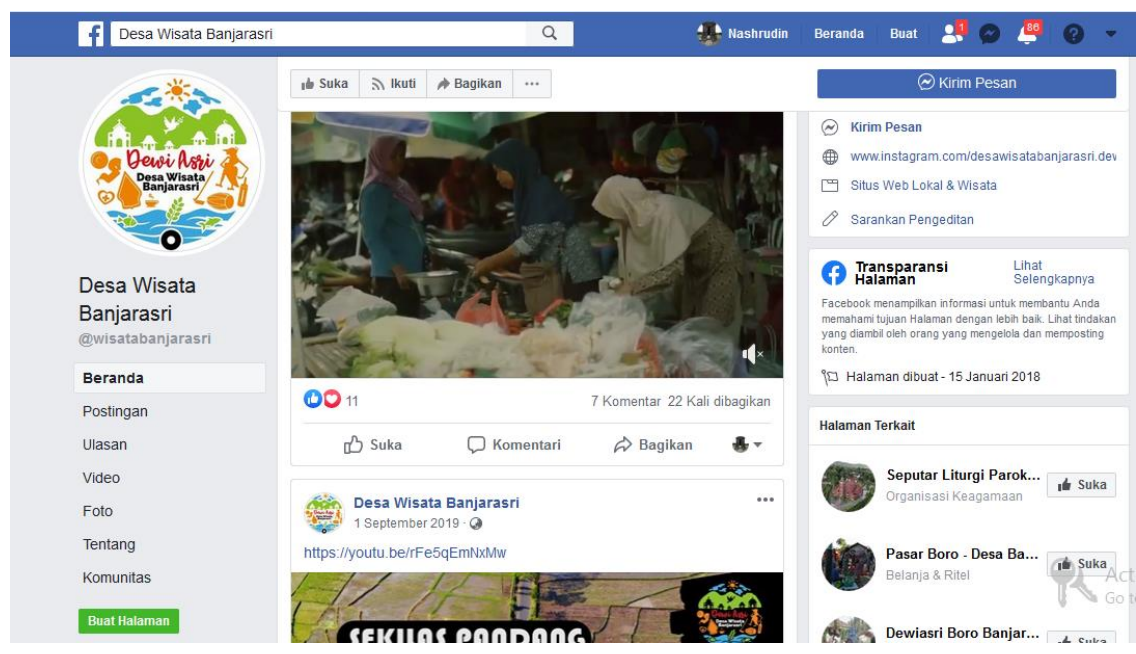

Gambar 4. Facebook

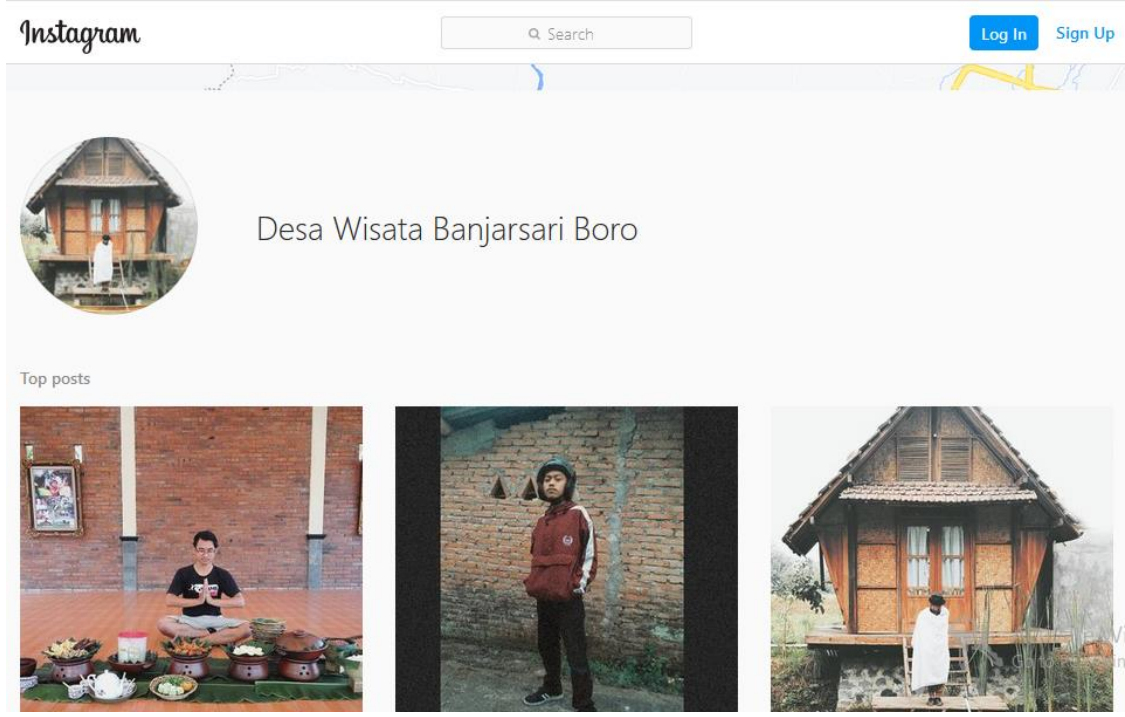

Gambar 5. Instagram

Penambahan untuk youtube sebagai contoh penggunaan media online diperlukan untuk menambah akses informasi desa wisata. Media tersebut untuk mengakomodir strategi pemasaran produk-produk UMKM sebagai penopang keberhasilan konsep desa wisata. Rencana strategis dilakukan secara holistik melalui optimalisasi media pemasaran online. Penggunaan media ini bertujuan untuk menciptakan pangsa pasar yang lebih luas melalui penambahan akses like dan subscribe sebagai indikator kinerja pemasaran online. Contoh peluang keterkaitan produk UMKM dengan konsep desa wisata sangat membantu aktivitas pemasaran berjalan optimum (Gambar 6). 
Jurnal Pengabdian Masyarakat

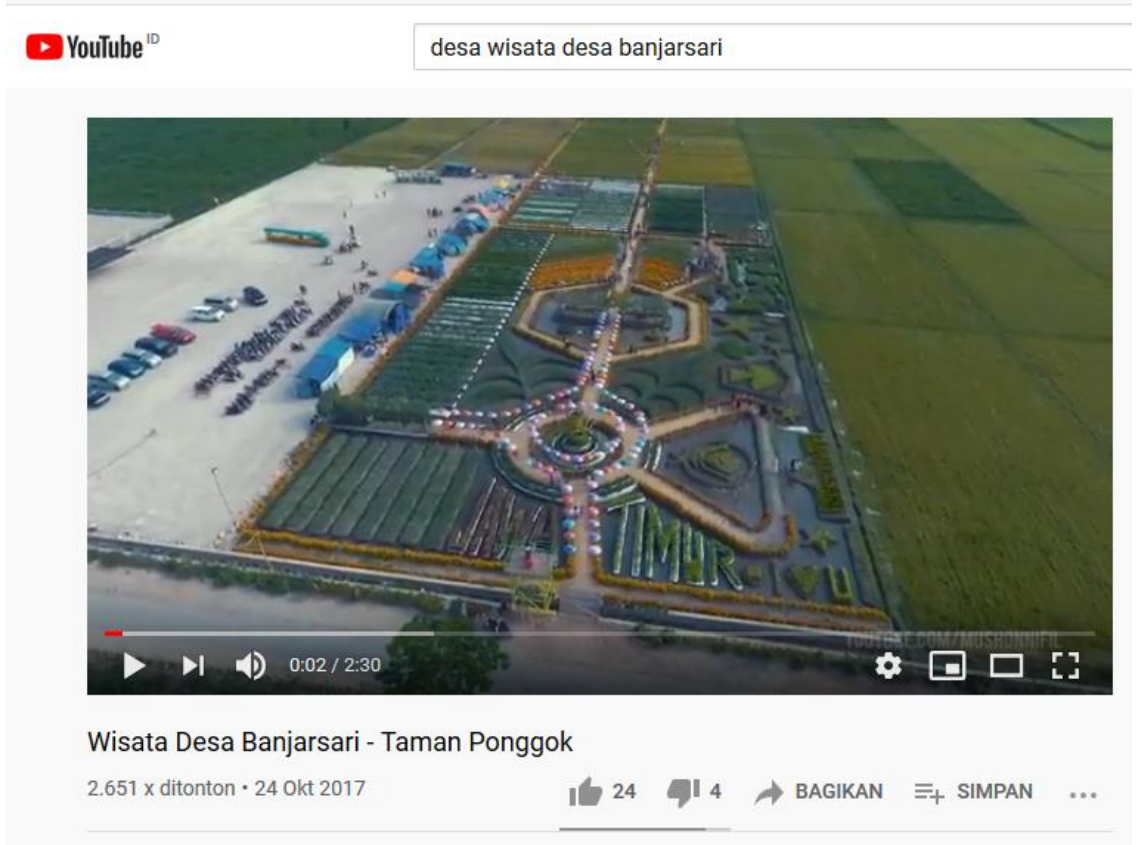

Gambar 6. Youtube

\section{DAMPAK DAN MANFAAT KEGIATAN}

Perencanaan strategis melalui kegiatan pengabdian masyarakat desa Banjarsari ditekankan pada upaya sistematis dan holistik. Pemasaran online dipilih untuk mengembangkan keterkaitan secara massif produk lokal UMKM dengan rencana strategis konsep desa wisata di tengah pandemi Covid-19. Konsistensi implementasi pemasaran online berdampak pada pengembangan kapabilitas dan kapasitas penggerak sumber daya yang dimiliki. Kolaborasi dalam pemberdayaan masyarakat desa diusahakan untuk meningkatkan distribusi kesejahteraan secara merata dan menunjang sepenuhnya program desa Banjarsari ke depan.

\section{SIMPULAN}

Pelaku UMKM sebagai peserta transfer pengetahuan pemasaran online di desa Banjarsari Kecamatan Manyar Kabupaten Gresik terlaksana dengan baik dalam kegiatan penyuluhan dan pendampingan. Kegiatan pengabdian masyarakat sebagai media pemberdayaan masyarakat adalah upaya mensinergikan potensi yang dimiliki desa Banjarsari dengan rencana strategis konsep desa wisata. Sinergi yang dibangun melalui pengenalan strategi pemasaran online yang ada mulai dari penggunaan website, facebook, instagram dan youtube dilakukan dengan sosialiasi dan transfer knowledge melalui penyadaran-penyadaran dalam mengembangkan produk UMKM dan konsep desa wisata berbasis digital marketing. Pengembangan pemasaran online diharapkan ke depan membutuhkan kapasitas dan kapabilitas yang mendukung baik dari segi sumber daya manusia dan tata kelola infastruktur $e$-marketing.

\section{UCAPAN TERIMA KASIH}

Tim pengabdian masyarakat Fakultas Ekonomi dan Bisnis menyampaikan terima kasih atas dukungan dana dari Lembaga Penelitian dan Pengabdian Masyarakat Universitas PGRI Adi Buana Surabaya sehingga kegiatan yang ditawarkan kepada mitra 
Jurnal Pengabdian Masyarakat

kerja berjalan baik dan memberikan manfaat bagi mitra kerja. Dukungan lain diberikan oleh Fakultas Ekonomi dan Bisnis serta tim dosen dalam mensukseskan kegiatan Penelitian dan Pengabdian Masyarakat.

\section{DAFTAR PUSTAKA}

Bambang. 2019. Strategi Optimalisasi Pemanfaatan e-Marketing Dalam Pemasaran Desa Wisata Karangsalam. Proseding Seminar Nasional dan Call for Papers

Edy, Imam Trisno, dkk. 2019. Pelatihan 'Online Marketing' Bagi Pelaku Usaha Di Kecamatan Laren Lamongan Dalam Rangka Pengembangan Desa Wisata Menjadi Destinasi Digital. MARTABE : Jurnal Pengabdian Masyarakat, Vol. 2, No.2

Hasan, Ali, \& Setiyaningtiyas, Niken Widiati. 2015. Pengaruh Electronic Word Of Mouth Pada Media Sosial Facebook Terhadap Keputusan Berkunjung Ke Desa Wisata Ngalnggeran Gunung Kidul. Jurnal Media Wisata, Volume 13 nomor 1

Harjito, Dwipraptono Agus; \& Golda, Nensi. 2018. KKN-PPM Pengembangan Desa Wisata Somongari di Kabupaten Purworejo Jawa Tengah. Asian Journal of Innovation and Entrepreneruship, Vol 03, Issue 03.

Irfanudin, dkk. 2020. Peran Seo Dalam Meningkatkan Reliabilitas Pemasaran Produk Via Media Online Pada Forum Muslimah Depok. Dedikasi PKM UNPAM, Vol.1, No.1

Kurnianti, Apsari Wahyu. 2018. Strategi Komunikasi Pemasaran Digital sebagai Penggerak Desa Wisata Kabupaten Wonosobo Provinsi Jawa Tengah. Jurnal Riset Komunikasi, Volume 1 Nomor 1: 180-190.

Lesmana, I Putu Dody, dkk. 2018. Pengembangan Pemasaran Online Kerajinan Anyaman Bambu Antirogo Jember Melalui Media Internet. Jurnal Bakti Masyarakat Indonesia Vol. 1, No. $1: 17-24$

Susyanti, Dewi Winarni. 2013. Potensi Desa Melalui Pariwisata Pedesaan. Jurnal Ekonomi dan Bisnis, 12(1) : 33 - 36.

https://republika.co.id/berita/nasional/daerah/16/04/21/o5zjzz336-dongkrak-potensiperikanan-gresik-kembangkan-kawasan-minapolitan, diakses 08 Agustus 2020 http://www.depkop.go.id/data-umkm, diakses 08 Agustus 2020 